Revue internationale de l'économie sociale

Recma

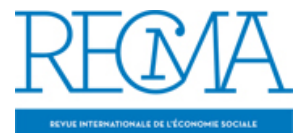

\title{
La coopération rurale en perspective internationale
}

\section{Jean-François Draperi}

Numéro 285, juillet 2002

URI : https://id.erudit.org/iderudit/1022245ar

DOI : https://doi.org/10.7202/1022245ar

Aller au sommaire du numéro

Éditeur(s)

Institut de l'économie sociale (IES)

ISSN

1626-1682 (imprimé)

2261-2599 (numérique)

Découvrir la revue

Citer ce document

Draperi, J.-F. (2002). La coopération rurale en perspective internationale. Revue internationale de l'économie sociale, (285), 4-4.

https://doi.org/10.7202/1022245ar d'utilisation que vous pouvez consulter en ligne.

https://apropos.erudit.org/fr/usagers/politique-dutilisation/ 


\section{LA COOPÉRATION RURALE EN PERSPECTIVE INTERNATIONALE}

es 14 et 15 décembre 2001 se sont tenus les Entretiens de Maraussan, à l'occasion du centenaire de la cave coopérative de Maraussan, dans l'Hérault (France). Ce numéro 285 de la Recma offre une sélection de contributions présentées lors de cette importante rencontre. Devant l'impossibilité de retenir l'ensemble des textes méritant d'être publiés, nous avons privilégié les textes sur la coopération agricole ayant une dimension internationale.

Les actes complets des Entretiens de Maraussan seront publiés dans les "Cahiers de l'économie sociale ", nouvelle collection d'ouvrages que nous créons dans le cadre d'une coédition entre L'Harmattan et l'Institut de l'économie sociale.

Le premier de ces cahiers sortira cet été. Coordonné par André Chomel, il est consacré à l'œuvre de Claude Vienney.

Jean-François Draperi 